\title{
Class III Subdivision Malocclusion With Unilateral Posterior Crossbite Suresh R
}

Department of Orthodontic

Adhi Parasakthi Dental College and Hospital

Melmaruvathur, Tamilnadu, India

Corresponding Author

Ramamurthy Suresh

Department of Orthodontic

Adhi Parasakthi Dental College and Hospital

Melmaruvathur, Tamilnadu, India

E-mail: sureshortho11@g.mail.com

\begin{abstract}
This article describes the management of class III subdivision malocclusion with unilateral left side posterior crossbite in an adolescent girl, using rapid palatal expansion followed by extraction of four premolars with comprehensive fixed appliance mechanotherapy.
\end{abstract}

\section{KEY WORDS}

Class III subdivision, posterior crossbite, rapid palatal expansion, second premolar extraction

\section{Citation}

Suresh R. Class III Subdivision Malocclusion With Unilateral Posterior Crossbite. Kathmandu Univ Med J 2014;47(3): 207-10.

\section{INTRODUCTION}

Angle first published his classification of malocclusion in 1899 based only on the dental arch relationship using study casts. ${ }^{1}$ According to Angle, class I occlusion occurred when the mesiobuccal cusp of the upper first permanent molar occluded on the buccal groove of the lower first molar. Class III malocclusion occurred when the lower teeth occluded mesial to their normal relationship approximately the width of one premolar or even more in extreme cases. Class III subdivision malocclusion have a normal occlusal relation on one side of the arches and a class III occlusion on the other side. ${ }^{2}$ Posterior crossbite usually involves the lingual displacement of a maxillary tooth and the buccal displacement of an occluding mandibular tooth. Posterior crossbites, as observed in centric occlusion, fall into two categories: unilateral and bilateral. Most patients who have a unilateral posterior crossbite shift their mandible towards the side with the crossbite when closing into centric occlusion. The lateral functional shift means that the crossbite is in actuality, bilateral and therefore readily treatable with an appliance that moves both sides of the upper arch buccally. Posterior crossbite can be corrected in adolescents with good success; however, older adolescents and adults are often resistant to expansion because the more ossified midpalatal suture of adults is more difficult to separate. Furthermore, the resistance of bony tissue and other soft tissues increases the tendency for relapse..$^{2-5}$ This paper discusses the management of transverse and anteroposterior problems with rapid palatal expansion and orthodontic fixed appliance respectively.

\section{CASE REPORT}

A 13 year old girl came to Adhiparasakthi Dental College and Hospital with a chief complaint of crooked upper and lower front teeth. Patient's parent gave a history of thumb sucking habit till ten years which was later stopped with the use of habit breaking appliance. Her medical history was non- contributory. Extraoral clinical examination showed a 


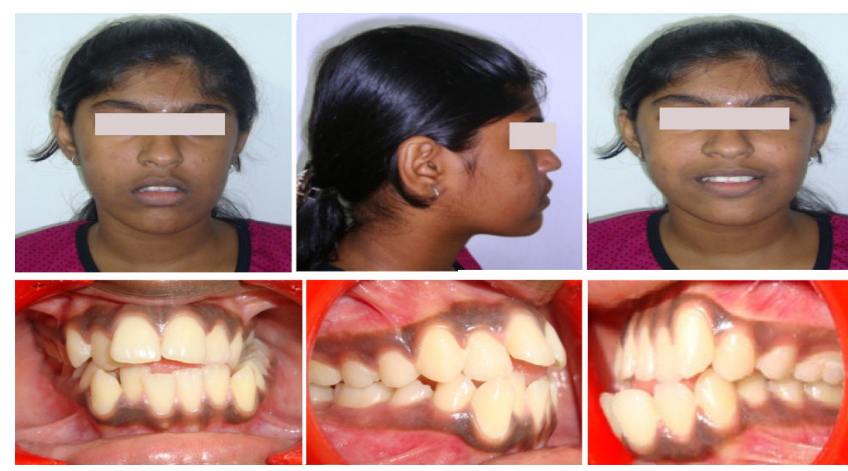

Figure 1. Pretreatment extraoral and intraoral photographs
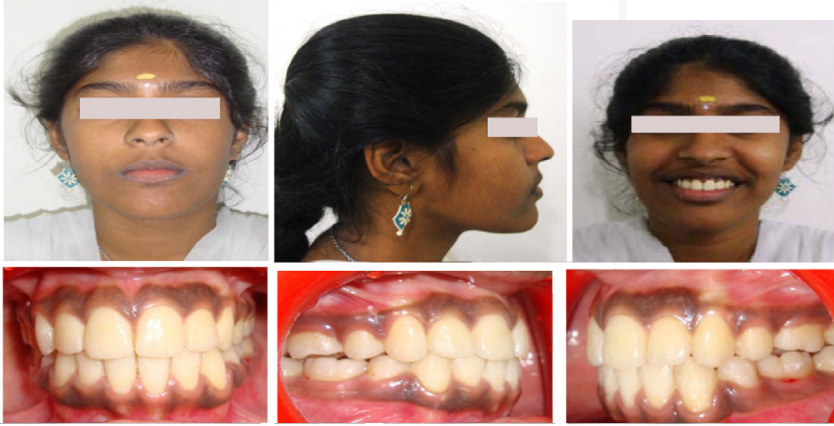

Figure 3. Posttreatment extraoral and intraoral photographs

class I facial pattern, with slightly strained lip competence and significant facial asymmetry. Intraoral examination revealed good oral hygiene status. She had a complete class III molar and canine relationship on the right side and a class I on the left side, with unilateral posterior crossbite on the left side. Anterior openbite of $2 \mathrm{~mm}$ was noticed. There was $7 \mathrm{~mm}$ of crowding in the mandibular arch and $3 \mathrm{~mm}$ in the maxillary arch. The curve of spee was mild (Fig 1). The maxillary dental midline was coincident to the facial midplane and the mandibular dental midline was deviated to the left side. Functional shift was present towards left side. The panoramic radiograph confirmed the presence of all permanent teeth and normal alveolar bone levels. Lateral cephalometric analysis showed class I skeletal base, high mandibular plane angle and slightly proclined upper and lower incisors (Fig 2).

The treatment objectives consist of correcting posterior unilateral skeletal crossbite, maxillary and mandibular crowding, midline deviation, functional shift and class III molar \& canine relation on right side. These changes would definitely improve her facial and dental esthetics significantly.

Based on the objectives, two treatment alternatives were planned. First the posterior unilateral crossbite would be corrected through rapid palatal expansion and extraction of two first premolars in the mandible and two second premolars in the maxilla. Second, rapid palatal expansion followed by extraction of single first premolar in the mandibular arch (left first premolar), maintain class III molar on right side and class I canine on left side. In this case, first option was selected to achieve all treatment objectives.
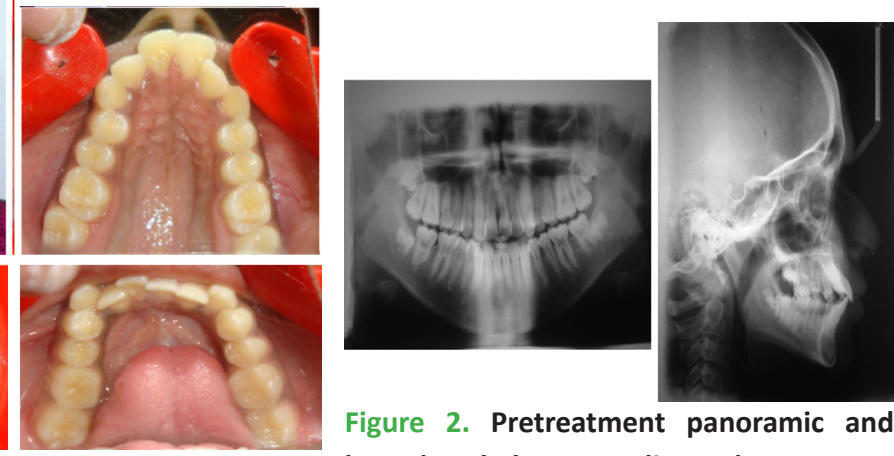

Figure 2. Pretreatment panoramic and lateral cephalogram radiographs
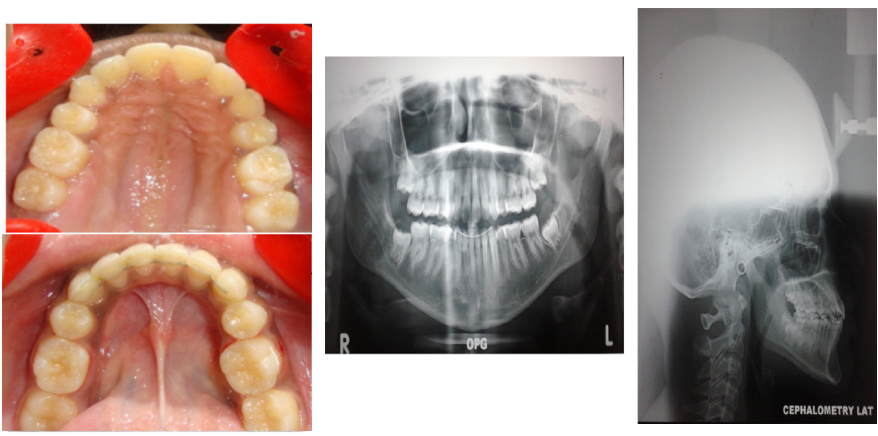

Figure 4. Postreatment panoramic and lateral cephalogram radiographs

Initially treatment was begun with bonded rapid palatal expansion appliance in maxillary arch. Patient was asked to activate the screw two turns per day. But patient couldn't activate as per the instruction and was unable to maintain the appointments. We called up the patient every weekend for activation. After eight months period we corrected unilateral crossbite but maxillary left second premolar and first molar were still on edge to edge relation. Midline discrepancy and functional shift were also improved. We left the rapid palatal expansion appliance for four months as a retainer in order to stabilize the correction. Eight months later, the two mandibular first premolars were extracted, bands were cemented on mandibular first molars and straight wire brackets were bonded from mandibular right second premolar to left second premolar ( ROTH version with a slot of $0.022 \times 0.028$ inch). Leveling and alignment in the mandibular arch was begun with 0.014 , followed by $0.016,17 \times 25$, and $19 \times 25$ Nickel Titanium archwire. Eighteen months later, extraction spaces were closed using sliding mechanics in $19 \times 25$ stainless steel wire. After rapid maxillary expansion was accomplished the expanded arch was maintained by soldered transpalatal arch with arms extended upto first premolar. Then second premolars on both right and left side in maxillary arch were extracted. After leveling and alignment transplatal arch was removed and space closure was done similar to mandibular arch. Class III intermaxillary elastics were used to protract maxillary first molar from class III into class I relation.

Active treatment to the planned position was completed after two years. Fixed retainers extending from canine to canine were used in mandible. A circumferential retainer in the maxillary arch was worn full time for the first six months following treatment, only at night thereafter. 
The intraoral photographs showed correct dental alignment, normal overjet and overbite, class I molar and canine relationship on both sides. Upper and lower dental midlines were coincident. The extraoral photographs showed improvement in facial profile, but facial asymmetry was still present (Fig 3). Patient and patient's parents were satisfied with the dental correction. The asymmetry that was still present at the end of the treatment did not create much concern for the patient and her parent. Cephalometric measurements of pre and post treatment values are shown in Table 1. The posttreatment panoramic radiograph showed root parallelism and intact supporting structures. Final lateral cephalogram revealed slightly increased mandibular plane angle and decreased upper and lower incisor protrusion (Fig 4).

Table 1. Cephalometric measurements of pre and post treatment values.

\begin{tabular}{|c|c|c|}
\hline & Pre- treatment & Post-treatment \\
\hline \multicolumn{3}{|c|}{$\begin{array}{l}\text { Sagittal Skeletal Rela- } \\
\text { tions }\end{array}$} \\
\hline SNA & 82 & 81 \\
\hline SNB & 79 & 80 \\
\hline ANB & 3 & 1 \\
\hline SNPog & 84 & 85 \\
\hline WITS & $\mathrm{AO}>\mathrm{BO}$ by $1 \mathrm{~mm}$ & $\mathrm{BO}>\mathrm{AO}$ by $0.5 \mathrm{~mm}$ \\
\hline \multicolumn{3}{|c|}{$\begin{array}{l}\text { Vertical skeletal rela- } \\
\text { tions }\end{array}$} \\
\hline SN/GoGn & 33 & 34 \\
\hline FMA & 29 & 30 \\
\hline \multicolumn{3}{|c|}{ Dental relations } \\
\hline $1-S N$ & 108 & 102 \\
\hline IMPA & 95 & 88 \\
\hline $1-1$ & 123 & 130 \\
\hline \multicolumn{3}{|c|}{ Soft tissue relations } \\
\hline Eline & $\begin{array}{l}\text { UL }-1 \mathrm{~mm} \\
\text { LL } 0 \mathrm{~mm}\end{array}$ & $\begin{array}{l}\mathrm{UL}-3 \mathrm{~mm} \\
\mathrm{LL}-1 \mathrm{~mm}\end{array}$ \\
\hline S line & $\begin{array}{l}\text { UL } 2 \mathrm{~mm} \\
\text { LL } 2 \mathrm{~mm}\end{array}$ & $\begin{array}{l}\text { UL } 0 \mathrm{~mm} \\
\mathrm{LL}+1 \mathrm{~mm}\end{array}$ \\
\hline
\end{tabular}

\section{DISCUSSION}

It is relatively easy to widen the maxilla by opening the midpalatal suture before and during adolescence, but this becomes progressively more difficult as patients become older. The chances of successful opening of the suture are nearly $100 \%$ before age 15 , but decline thereafter because of the increased interdigitation of the sutures..$^{5-7}$ Sutural expansion is more stable than dental tipping, therefore all efforts should be directed towards maximal suture opening and minimal dental tipping. There are two ways of separating midpalatal suture, either by rapid or slow expansion method. Rapid palatal expansion appliance was introduced by Emerson Angell in 1860 and later repopularized by Hass. ${ }^{8}$ Rapid palatal expander is used to correct skeletal posterior crossbite, increase arch perimeter, level the curve of Wilson, increase airway patency and
Table 2. Comparsion of maxillary arch width changes before and after expansion.

\begin{tabular}{|lcc|}
\hline Maxillary arch & Before expansion & After expansion \\
\hline Intercanine distance & 25 & 32 \\
\hline Inter second premolar & 28 & 33 \\
\hline Inter first molar & 29 & 33 \\
\hline
\end{tabular}

broaden the smile. ${ }^{9}$ Rapid palatal expansion is indicated in cases with transverse discrepancy equal to or greater than $4 \mathrm{~mm}$ and where the maxillary molars are buccally inclined to compensate for transverse skeletal discrepancy.

Rapid palatal expansion is classified into bonded and banded type. Compared to banded type, bonded expander has got two potential advantages - occlusal force acting against the acrylic over the posterior teeth reduces the amount of extrusion and downward - backward rotation of the mandible, which is more important in long face patient. ${ }^{4}$ In this case we selected bonded type for the above reason. Brust has shown that little tooth tipping is observed in bonded expander, presumably due to the rigid framework and bonding of the appliance to the posterior dentition. ${ }^{10}$

Adkins and colleagues have examined the relationship between arch expansion and changes in arch perimeter and have shown that every millimeter of transpalatal width increase in the premolar region produces a $0.7 \mathrm{~mm}$ increase in available arch perimeter. ${ }^{11}$ Ideal transpalatal width in the adult patient with a class I normal occlusion and average sized teeth is $35-39 \mathrm{~mm}$. Similarly, a transpalatal width of 33-35 $\mathrm{mm}$ can be considered ideal for a patient during the mixed dentition period. ${ }^{12}$ Changes in maxillary arch width before and after treatment are shown in Table 2.

Extraction of second premolar was first introduced by Nance in $1949 .{ }^{13}$ Nance suggested that borderline extraction cases with minimal crowding and cases to avoid over- retraction of the anterior segments should be treated in conjunction with extraction of second premolars. Schoppe and Schwab observed that more mesial movement of the posterior segments were present in second premolar extractions cases than in first premolar extraction. ${ }^{14,15}$ In some class III cases with crowding, treatment may be easier to consider extraction of upper second and lower first premolars. ${ }^{16}$

In this case, Group C in upper and Group A anchorage in lower arch was planned. So, second premolars in upper arch and first premolars in lower arch were removed. Decrowding and anterior teeth retraction was made easy by first premolar extraction in lower arch. Acrylic bite block helps in correction of midline discrepancy and functional shift. Second premolar extraction favors posterior protraction of teeth in upper arch.

\section{CONCLUSION}

This article demonstrates that class III subdivision malocclusion with posterior unilateral crossbite can be successfully managed using bonded rapid palatal expansion 
followed by fixed orthodontic treatment. Careful case selection and excellent patient cooperation could ensure a treatment result that is stable, functional and esthetic for a long term.

\section{REFERENCES}

1. Angle EH. Classification of malocclusion. Dental cosmos 1899;41:248.

2. Robert N. Staley. Orthodontics diagnosis and treatment planning. In: Bishara SE, editor. Textbook of orthodontics. Saunders Elsevier;2007.p.103.

3. Bishara SE, Staley RN. Maxillary expansion: clinical implications. Am J Orthod Dentofacial Orthop. 1987;91(1):3-14.

4. Hayes JL: Rapid maxillary expansion. Am J Orthod Dentofacial Orthop. 2006;130(4):432-3.

5. Proffit WR, Fields HW, Sarver DM. Contemporary orthodontics. $4^{\text {th }}$ edn. St. Louis:Mosby; 2009.p.560-62.

6. Melsen B. Palatal growth studied on human autopsy material. A histologic microradiographic study. Am J Orthod Dentofacial Orthop. 1975;68:42-54

7. Melsen B, Melsen F. The postnatal development of the palatomaxillary region studied on human autopsy material. Am J Orthod Dentofacial Orthop. 1982;82:329-342.

8. Donald J Timms. The Dawn of rapid maxillary expansion. Angle Orthod 1999;69(3):247-50.

9. McNamara JA, Jr. An orthopedic approach to the treatment of class III malocclusion in young patients. J Clin Orthod. 1987;21:598-608.
10. Brust EW. Arch dimensional changes concurrent with expansion in the mixed dentition. Ann Arbor: Unpublished Master thesis, Department of Orthodontics and Pediatric Dentistry, The University of Michigan;1992.

11. Adkins MD, Nanda RS, Currier GF. Arch perimeter changes on rapid palatal expansion. Am J Orthod Dentofacial Orthop.1990;97:194-9.

12. Howe RP, McNamara JA,Jr, O' Connur KA. An examination of dental crowding and its relationship to tooth size and arch dimension. Am J Orthod Dentofacial Orthop. 1983;83:363-373.

13. Nance HN. Removal of second premolars in orthodontic treatment. Am J Orthod. 1949;35:685-696.

14. Schoppe RJ. Analysis of second premolar extraction procedures. Angle Orthod. 1964;34:294-302.

15. Schwab DT. The borderline patient and tooth removal. Am J Orthod. 1971;59:126-45.

16. Burcu Bayirli, Christopher S. Riolo, Michelle Thornberg, Michael L. Riolo. Treatment tactics for problems related to dentofacial discrepancies in three planes of space. In: Jeryl D. English, editor. Moyer's orthodontic review: St.Louis: Mosby; 2009.p.134 